\title{
ВИХРЕВОЕ СМЕШИВАНИЕ ГОРЮЧИХ ГАЗОВ С РАЗЛИЧНЫМИ \\ ГАЗООБРАЗНЫМИ И АЭРОЗОЛЬНЫМИ ДОБАВКАМИ, КАК ЧАСТЬ ПРОЦЕССА «УМНОГО» СГОРАНИЯ
}

\section{Игнатенкова Анна Игоревна}

Формирование из потоков горючих газов перед впрыском в камеру сгорания вихревой трубы из различных газообразных компонентов и аэрозолей, позволяет значительно улучшить термодинамические параметры процесса горения.

Так как такой подготовительный процесс является достаточно новым, автор счёл важным привести информацию об особенностях и порядке тестирования устройства для смешивания в динамике природного газа со сжатым воздухом и перегретым паром, перед подачей смеси в камеру сгорания индустриального бойлера.

Представим, что мы располагаем устройством для вихревого смешивания газообразных компонентов и аэрозолей, и весь процесс испытаний готовим, исходя из условий и характеристик указанного устройства.

Цель и порядок испытаний.

Целью испытаний является проверка в реальных условиях характера воздействия вихревой трубы из газообразных топливных компонентов на все основные параметры процесса сгорания.

В качестве объекта, на котором предполагается провести испытания, предложен бойлер с выходной мощностью в 50 киловатт.

Газообразную топливную смесь предполагается приготовить в режиме онлайн из потока горючего газа, смешанного в процессе подачи в камеру сгорания с перегретым паром.

Смешивание и формирование вихревой трубы из газообразного топлива и перегретого пара предполагается вести в специальном устройстве (которое 
должно содержать более двух вихревых генераторов, подключённых последовательно) и подсоединённого к генератору перегретого пара, который также должен быть подобран, исходя из технической характеристики специального устройства.

Предварительные расчёты параметров генератора пара, исходя из параметров бойлера с выходной мощностью в 50 киловатт, должны быть промоделированы при помощи методов компьютерного моделирования в рамках возможностей компьютерных программ, по которым выполнялось проектирование устройства и всего испытательного стенда.

Для формирования достоверной базы для сравнения результатов, предполагается выполнить базовые тесты и испытания на бойлере такой же мощности с таким же газообразным горючим материалом (топливом), который предполагается смешивать с паром в тестируемом устройстве для вихревого смешивания.

Базовые тесты предполагается выполнить при малой, средней и максимальной нагрузке бойлера.

При базовом тесте необходим четкий контроль и максимально возможное точное измерение концентраций всех веществ в выхлопных газах в соответствии с требованиями действующих стандартов. Все приборы для измерений должны быть аттестованными в соответствующих контрольных и измерительных лабораториях.

При базовом тесте необходимо предельно возможное, точное измерение параметров процесса горения в камере сгорания бойлера, в том числе такие параметры и показатели, как:

- расход топлива,

- расход воздуха,

- расход избыточного воздуха,

- температура пламени, 
- температура выхлопных газов,

- полученная выходная мощность,

- тепловые потери,

- температура окружающей среды,

- влажность воздуха,

- атмосферное давление,

- давление газа в магистрали.

При базовом тесте, также отдельно проверяется работа генератора перегретого пара, и измеряются его параметры.

Для этого теста также все приборы для измерений должны быть поставлены от независимой лаборатории и должны соответствовать требованиям и спецификациям действующих стандартов, технических условий и утверждённых технических требований. Все приборы и контрольно-измерительное оборудование должны иметь сертификацию и рабочие паспорта с отметками об предыдущих проверках и аттестациях.

Крайне желательно иметь возможность проверить параметры горения при использовании форсунок различного типа и метода распыления, фотографировать факел распыла для различных форсунок и факел пламени для различных форсунок.

Первая стадия контрольного тест - процесса (обязательная).

Все вышеизложенные контрольные операции необходимо повторить при опытном и при контрольном тестировании:

- при подаче того же топлива,

- при подаче того же топлива, но смешанного с перегретым паром в различных пропорциях смешивания с газообразным топливом,

- при подаче того же топлива, смешанного с перегретым паром в тех же пропорциях, но для различных типов нагрузки бойлера (низкой), 
- при подаче того же топлива, смешанного с перегретым паром в тех же пропорциях, но для различных типов нагрузки бойлера (средней),

- при подаче того же топлива, смешанного с перегретым паром в тех же пропорциях, но для различных типов нагрузки бойлера (высокой).

Вторая стадия контрольного тест - проекта (опциональная).

Все вышеизложенные операции необходимо повторить при контрольном тестировании:

- при подаче того же топлива,

- при подаче того же топлива, но смешанного со сжатым воздухом в различных пропорциях смешивания с газообразным топливом,

- при подаче того же топлива, но смешанного со сжатым воздухом в тех же пропорциях, но для различных типов нагрузки (низкой),

- при подаче того же топлива, но смешанного со сжатым воздухом в тех же пропорциях, но для различных типов нагрузки (средней),

- при подаче того же топлива, но смешанного со сжатым воздухом в тех же пропорциях, но для различных типов нагрузки (высокой).

По результатам контрольных тестов должен быть составлен тест-протокол со сравнительными диаграммами, согласованный и подписанный всеми участниками тест-проекта (обязательно).

По результатам тестов должен быть составлен аналитический отчёт, согласованный и подписанный всеми участниками тест-проекта (опционально). 


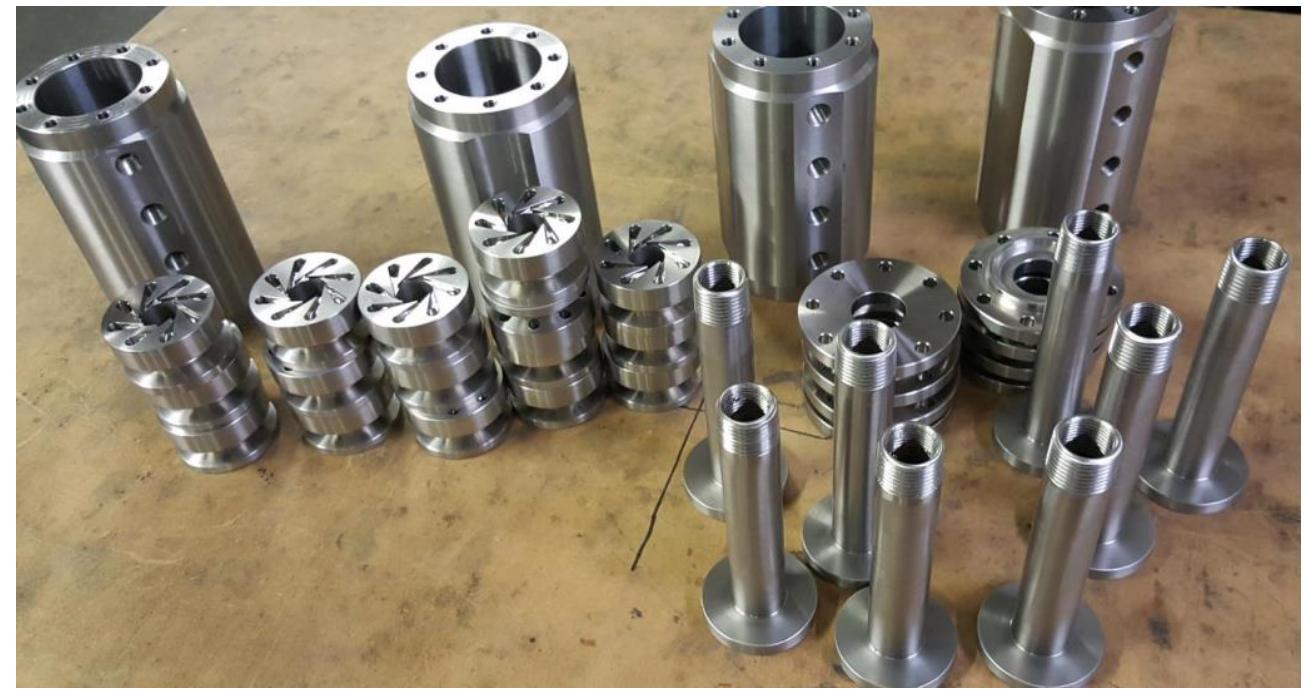

Рисунок 1. Полученные в условиях серийного производства на станках и обрабатывающих центрах - детали минимального размера устройства для вихревого смешивания газов и аэрозолей

Как видно из рисунка, устройство содержит 4 последовательно расположенных вихревых генератора. Каждый вихревой генератор содержит 8 тангенциальных каналов, каждый из которых формирует одну вихревую спираль, из которых формируется общая вихревая труба.

Практически на каждый вихревой генератор можно подавать другой компонент смеси, так как 8 вихревых спиралей достаточно, чтобы получить устойчивую вихревую трубу на выходе и входе в камеру сгорания бойлера.

Этот фактор существенно расширяет техническую характеристику устройства, что в свою очередь также расширяет область использования технологии вихревого смешивания. 


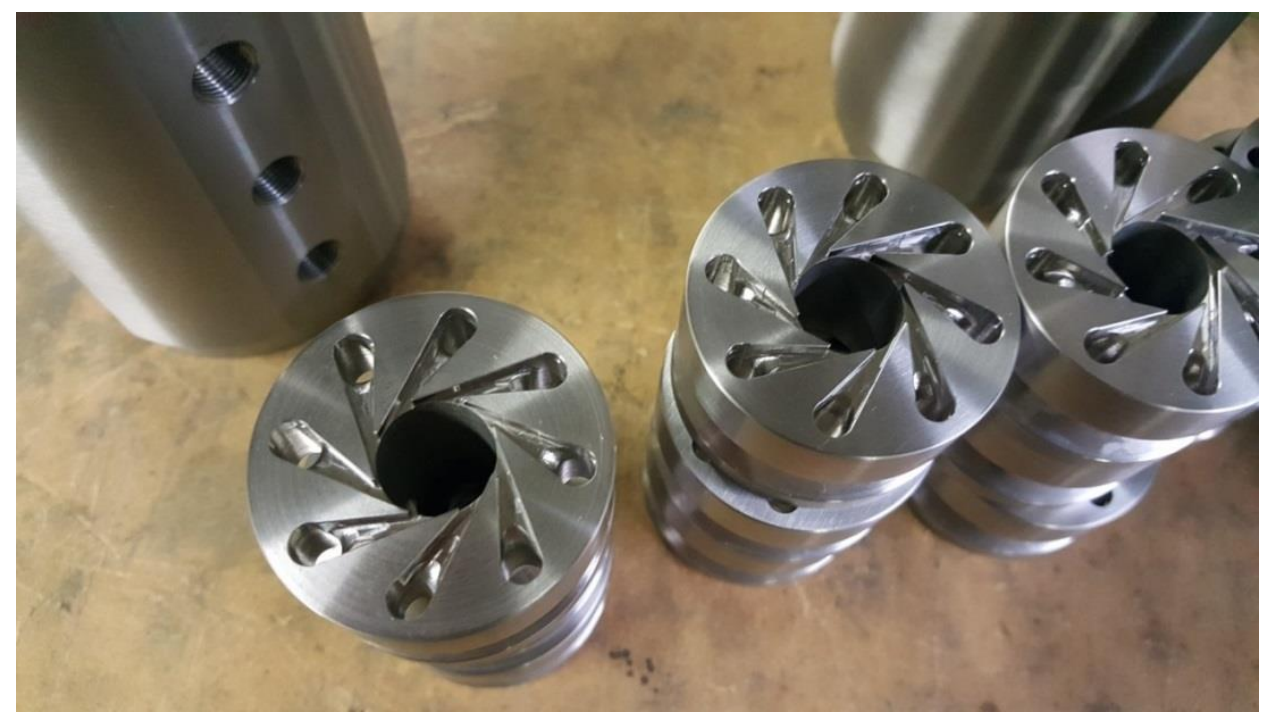

Рисунок 2. Вихревые генераторы с 8 тангенциальными каналами, для формирования на каждом 8 вихревых спиралей

Таким образом, если устройство содержит 4 вихревых генератора, и каждый вихревой генератор формирует 8 вихревых спиралей, то в совокупности всё устройство формирует вихревую трубу, состоящую из 32 спиралей.

Так как диаметры подводящей трубы и диаметр отводящей трубы составляет только 15 мм, можно считать, что это устройство относится к категории малых, с соответствующей пропускной способностью и габаритными и присоединительными размерами.

Применение устройств вихревого смешивания практически не создаёт какихлибо ограничений на функционирование топливных магистралей бойлера, в которых монтируется это устройство и не ограничивает на входе количество компонентов топливной смеси газов или аэрозолей.

\section{Диаграмма 1}

Общий вид устройства для вихревого смешивания топливных смесей. Устройство формирует при смешивании вихревую трубу из газообразных компонентов топлива и может работать онлайн в прямой инсталляции в термодинамическом оборудовании. 


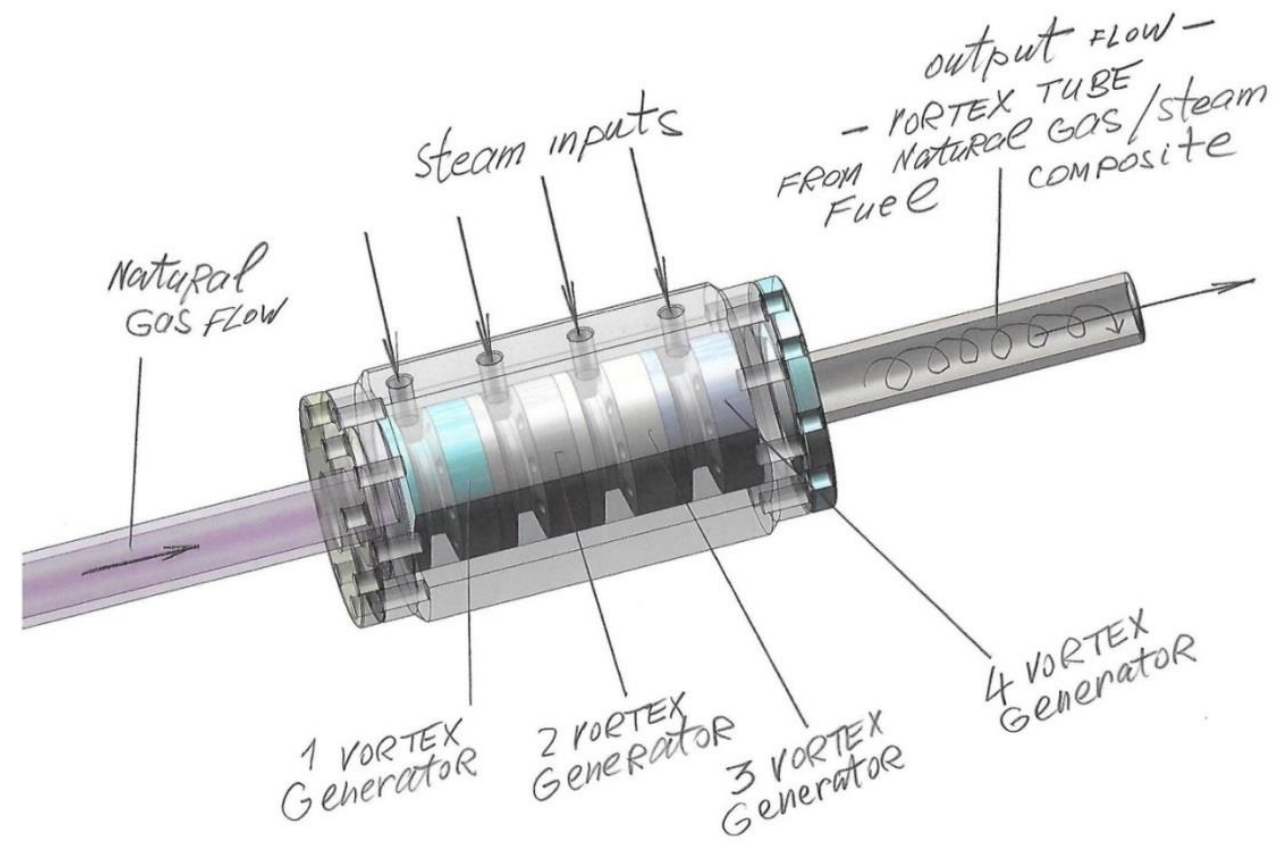

Минимальные габаритные размеры устройства - диаметр 15 мм в центральном подводящем природный газ трубопроводе (на самом деле могут быть любые горючие газообразные виды топливных добавок).

Устройство, как уже указывалось выше, включает 4 вихревых генератора, каждый из которых имеет независимый вход газообразных компонентов. Как уже отмечалось, это могут быть - сжатый воздух, перегретый пар и пар, получаемый в самом бойлере.

В случае, когда в устройстве смешиваются различные виды и типы пара, устройство обладает способностью охлаждать поток газа, а в случае смешивания газа со сжатым воздухом, устройство имеет чётко выраженный охлаждающий эффект.

Как уже было отмечено ранее, в вихревых генераторах минимального размера устройства имеется 8 тангенциальных каналов, по которым практически равномерно распределяются потоки газообразных компонентов, подающихся на смешивание и активирование. 
Устройство для вихревого смешивания может иметь различное количество вихревых генераторов. При наличии 4 вихревых генераторов суммарное, совокупное число вихревых спиралей составляет - 32, которые создают достаточно стабильную вихревую трубу, демонстрирующую охлаждающий эффект, в соответствии с законом Джоуля - Томсона на периферии вихревой трубы, с законом Ранка - Хилша - в центре вихревой трубы.

Снижение температуры горючих газов, подающихся в камеру сгорания бойлера, положительно влияет на термодинамический баланс процесса сгорания и снижает температуру выхлопных газов, что также, кроме повышения стабильности процесса сгорания, снижает расход топлива и увеличивает общую эффективность бойлера.

\section{Диаграмма 2}

Диаграмма контрольных точек температуры для любой конфигурации испытательного стенда

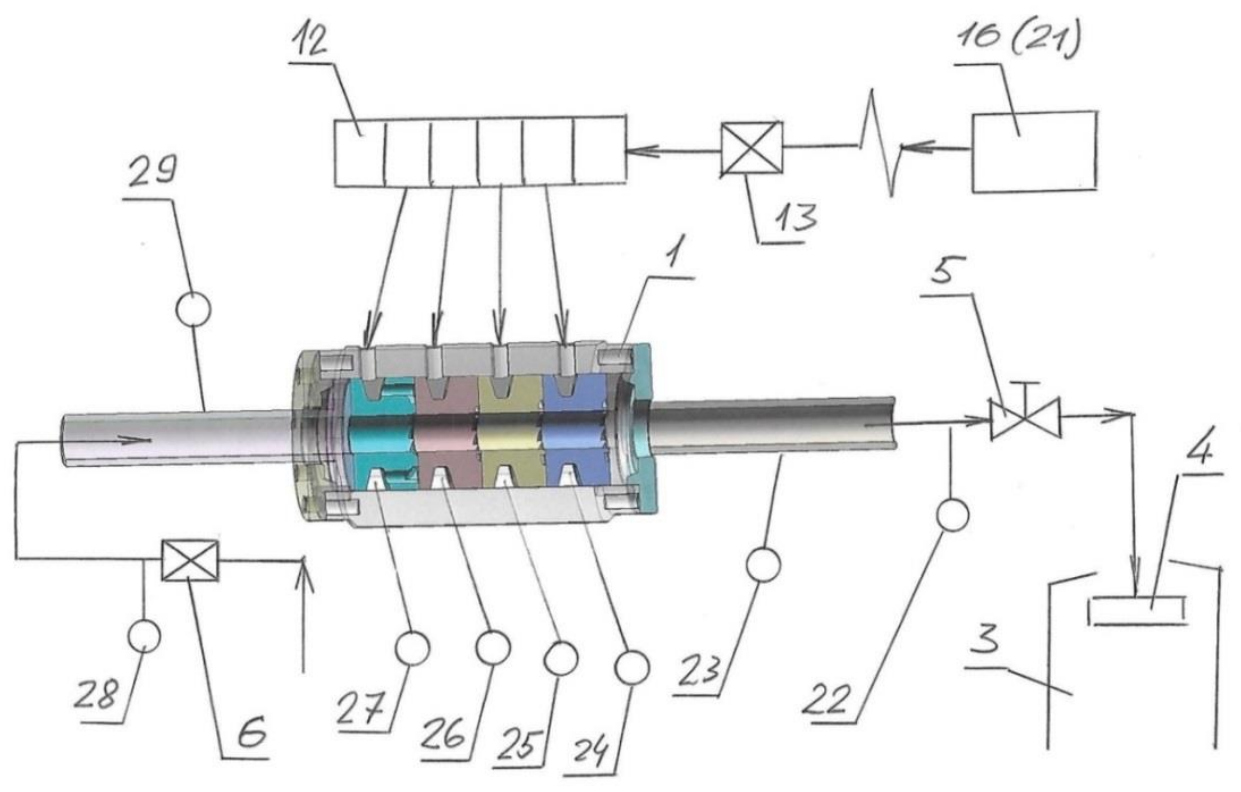

1 - устройство для вихревого смешивания газов,

3 - камера сгорания бойлера,

4 - форсунка или инжектор, 
5 - регулирующий клапан,

6 - обратный клапан,

12 - распределительный трубопровод,

13 - обратный клапан,

16 - компрессор или подключение к действующей линии сжатого воздуха,

21 - парогенератор или другой источник перегретого пара,

22- 29 - точки контроля температуры.

\section{Диаграмма 3}

Диаграмма испытательного стенда, в случае, если второй материал смеси перегретый пар

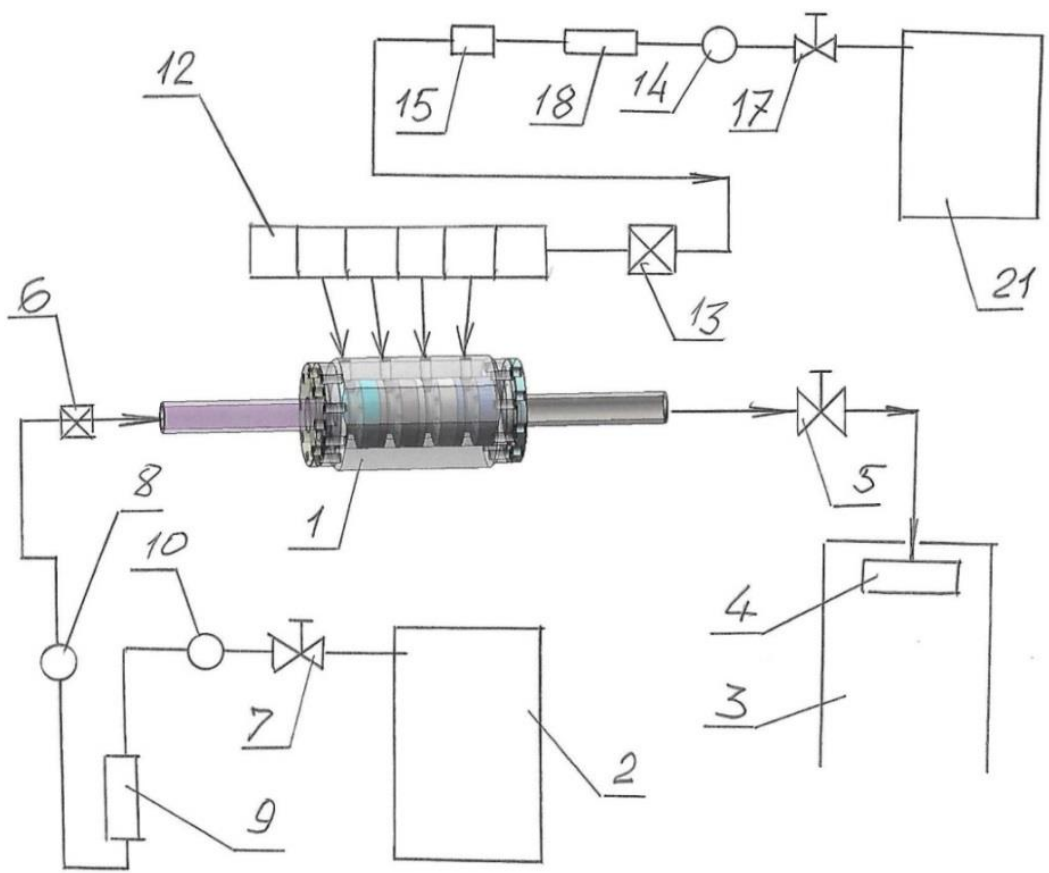

1 - устройство для вихревого смешивания с формированием вихревой трубы,

2 - источник подачи природного газа,

3 - камера сгорания бойлера,

4 - форсунка или инжектор,

5 - регулирующий клапан, 
6 - обратный клапан,

7 - регулирующий клапан,

8 - манометр,

9 - датчик расхода - расходомер,

10 - линейный термометр,

12 - распределительный трубопровод,

13 - обратный клапан,

14 - манометр,

15 - обратный клапан,

17 - регулирующий клапан,

18 - датчик расхода,

21 - генератор пара.

Bce схематические примеры и приведенные детальные диаграммы могут быть реализованы в рамках стандартного дизайнерского процесса при помощи стандартных конструкторских программ.

Все компоненты и приборы испытательного стенда являются стандартными и могут быть собраны, отрегулированы и настроены специалистами среднего уровня и квалификации.

Принципиальные решения, изложенные на диаграммах, позволяют выполнить, при необходимости, весь цикл детального дизайна деталей и элементов испытательного стенда.

Для управления системой при эксплуатации, система автоматического управления и контроля бойлера, может быть модифицирована и в неё могут быть интегрированы элементы искусственного интеллекта и искусственные нейронные сети, которые могут оптимизировать процесс онлайн управления и контроля параметрами работы бойлера в режиме реального времени. 


\section{Диаграмма 4}

Диаграмма испытательного стенда для случая, когда второй материал смеси сжатый воздух.

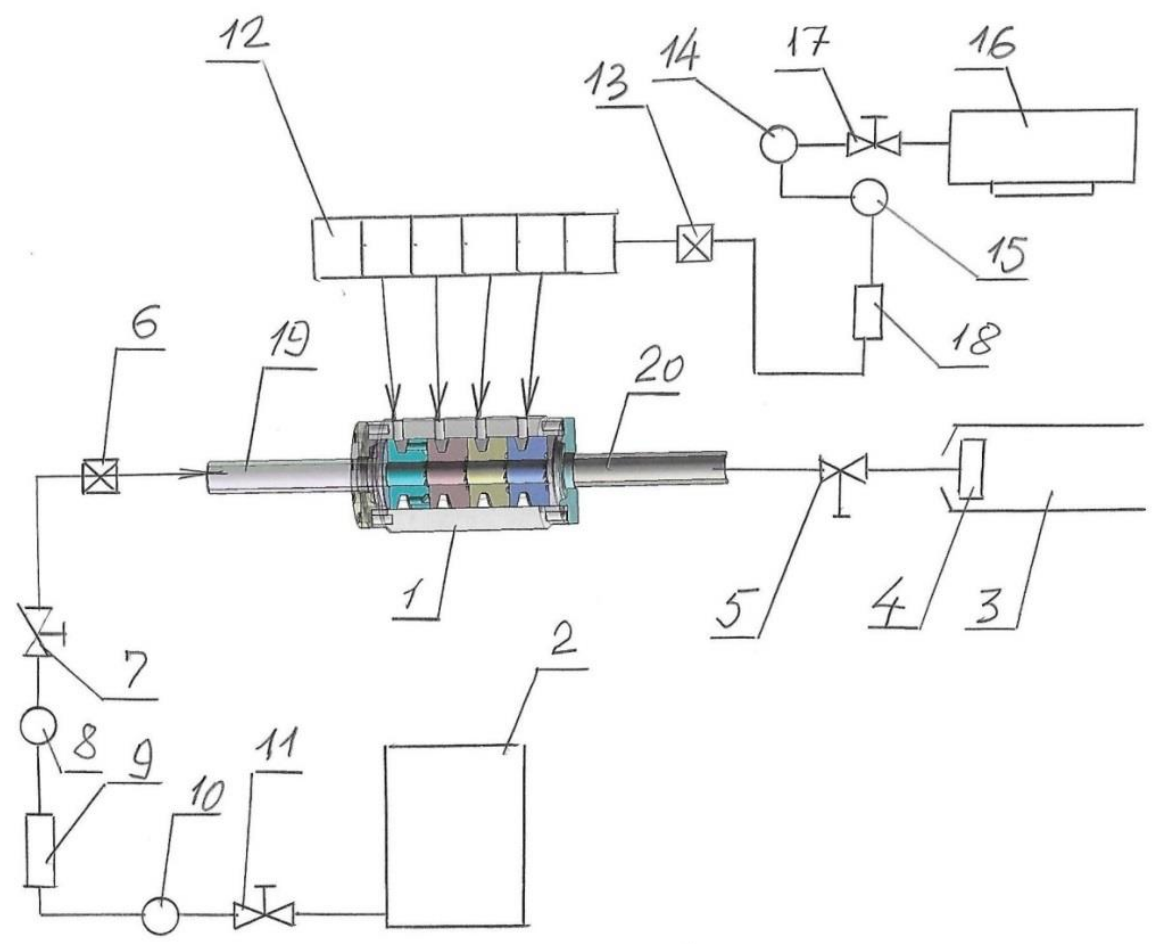

1 - устройство для вихревого смешивания газов,

2 - источник природного газа,

3 - камера сгорания бойлера,

4 - форсунка или инжектор,

5 - регулирующий клапан,

6 - обратный клапан,

7 - регулирующий клапан,

8 - манометр,

9 - датчик расхода,

10 - линейный термометр,

11 - регулирующий клапан,

12 - распределительный трубопровод или ресивер,

13 - обратный клапан, 
14 - манометр,

15 - линейный термометр,

16 - компрессор,

17 - регулирующий клапан,

18 - датчик расхода,

19 - система трубопроводов для ввода в устройство для вихревого смешивания,

20 - система трубопроводов для вывода из устройства для вихревого смешивания. 


\section{Список используемых материалов:}

1. United States Patent Application 20190203626, A1, July 4, 2019, ABHYANKAR Atul S.; RESONANT MIXERS FOR REDUCING REDUCTANT DEPOSITS.

2. United States Patent Application 20180094772, A1, April 5, 2018, SANTOS Pedro T.; VIRTUAL GASEOUS FUEL PIPELINE.

3. United States Patent Application 20060213223, A1, September 28, 2006, WILDING Bruce M.; APPARATUS FOR THE LIQUEFACTION OF NATURAL GAS AND METHODS RELATING TO SAME.

4. United States Patent Application 20150000757, A1, January 1, 2015, BAYLIFF Todd Allan; METHODS AND SYSTEMS FOR REDUCING PRESSURE OF NATURAL GAS AND METHODS AND SYSTEMS OF DELIVERING NATURAL GAS.

5. United States Patent Application 20110061391, A1, March 17, 2011, KENDRICK Donald W.; VORTEX PREMIXER FOR COMBUSTION APPARATUS.

6. United States Patent Application 20100263385, A1, October 21, 2010, ALLAM Rodney J.; GENERATING POWER FROM NATURAL GAS WITH CARBON DIOXIDE CAPTURE.

7. United States Patent Application 20090020456, A1, January 22, 2009, TSANGARIS Andreas; SYSTEM COMPRISING THE GASIFICATION OF FOSSIL FUELS TO PROCESS UNCONVENTIONAL OIL SOURCES.

8. United States Patent Application 20160107890, A1, April 21, 2016, ALLAM Rodney J.; GENERATING POWER FROM A NATURAL GAS WITH CARBON DIOXIDE CAPTURE.

9. United States Patent Application 20100269516, A1, October 28, 2010, BRAUTSCH Andreas; METHOD FOR OPERATING A GAS TURBINE INSTALLATION AND EQUIPMENT FOR CARRYING OUT THE METHOD.

10. United States Patent Application 20150119478, A1, April 30, 2015, BOWE Michael Joseph; GAS-TO-LIQUID TECHNOLOGY. 